\section{A GLIMPSE INTO THE LEVEL OF FINANCIAL INCLUSION IN TRIPURA}

KEY WORDS: Index Of

Financial Inclusion, Banking Penetration, Availability Of Banking Services, Usage.

\section{Dr. Sayan Saha*}

Dr. Kiran

\section{Shankar Chakraborty}

Faculty, Maharaja Bir Bikram University, Agartala, Tripura (West), India. *Corresponding Author

Regional Director, IGNOU, Agartala-799004,Tripura, India.

The term 'Financial Inclusion' signifies a process of ensuring delivery of financial services as well as banking services to the vulnerable groups at the point of need, adequately at an affordable cost. The concept of 'Financial Inclusion' was accentuated in 2003 by Kofi Annan, former General Secretary of United Nations. Such, efforts were undertaken by the Reserve Bank of India (RBI) in 2005 and the said policy as already mentioned in a pilot project was first implemented by Indian Bank. Probably, by implementing such policy resolution a vast section of the rural disadvantaged people in India was gradually coming under the ambit of formal banking services. The main aim of this paper is to assess the level of financial inclusion in Tripura based on composite Index. The study conducted in the four districts of Tripura state. The present study relies on secondary data. Secondary data collected from State Level Bankers' Committee Reports, NEDFi databank, Economic Reviews and RBI Annual Reports. Through this paper Index of Financial Inclusion (IFI) has been used to assess the level of financial inclusion in Tripura.

\section{INTRODUCTION}

Financial Inclusion is the process of involving a range of policies aimed at promoting equality of access to financial services at an affordable cost for the people. In a simple term, it's a process to reduce the problems of financially excluded people such as inability, difficulty to access and/or use financial services (Mitton, 2008 \& European Commission Report, 2008). It is one of the important components to bringing opportunities for the rural backward and lowincome disadvantaged sections of the society with in the banking fold and it also to take part into the inclusive growth as a sustainable economic development of financial system. A number of authoritative definitions have been pronounced by different bodies like United Nations, World Bank, Asian Development Bank, Treasury Committee House of Commons, UK and so on. And each of their definitions stresses own set of indicators in conceptualizing the process although; on the whole, all the definitions are interlinked. However, the definition of Financial Inclusion/Exclusion developed by Asian Development Bank is found to be more relevant for the study and accordingly, the indicators, namely, Deposit, Loans, Payment services, Money transfer and Insurance being considered important in the present study and these have been considered in building up the research model here in this study.

\section{LITERATURE REVIEW AND RESEARCH GAP}

Sarma (2008) in "Index of Financial Inclusion" has attempted to develop the measure that can be used in indexing the extent of financial inclusion across the countries. In her crosscountry analysis she has used banking inclusion as analogous to financial inclusion. She has used three dimensions of financial inclusion viz. banking penetration, availability of banking services and usage. This multi-dimensional measurement technique was also facilitates to build an empirical relationship between inclusive financial system and sustainable economic growth of underprivileged community within across nations.

Chakravarty and Pal (2010) in the study on "Measuring Financial Inclusion: An Axiomatic Approach" examined that the axiomatic measurement approach can be usefully applied to the measurement of Financial Inclusion. In this paper they have developed a conceptual framework for aggregating data on financial services with various dimensions. Thus the Financial Inclusion Index allows to compute percentage of contributions of different dimensions to the overall achievement and the suggested Index helps us to identify the inclusion dimensions which are more or less vulnerable to overall inclusion. Hence, to separate the dimensions that deserve attention from a policy viewpoint. This paper aims to focus on the methods of Index for measuring financial inclusion using cross country and sub-national level data.

Chattopadhyay (2011) in "Financial Inclusion in India: A casestudy of West Bengal" the main objective of the study was to focus upon the extent of financial inclusion in West Bengal. In this study the author used a three set of dimensions to measure the Index of Financial Inclusion for 23 states in India and 18 districts of West Bengal state for the period of 20062009. However, it has been observed that there were near about 38 percent of rural respondents agreed the major barrier of the rural financial inclusion is the lack of sufficient rural income. It has been also found that the informal sources of finance were also dominating the formal banking services in the rural areas. The study suggested that supply side factors and demand side factors are equally important to enhance the inclusive finance through implementing the policy of financial inclusion.

Demirguc-Kunt and Klapper (2012) in "Measuring Financial Inclusion-The Global Findex Database" had made an attempt to analyse the global financial inclusion in across countries by using a four set of indicators (formal accounts, savings behaviors, sources of formal and informal borrowings and insurance services). From the results of the study, it can be concluded that a half of the total adult population within 148 countries still do not have a formal account and they had faced a common barriers of financial inclusion such as-high cost of informal sources of borrowings, physical distance of bank branches and lack of adequate documents to open a bank account.

The forgoing review of available literature reveals that the studies on Financial Inclusion are very limited especially in the context of North Eastern Region of India. The studies on parameters of Financial Inclusion or level of Financial Inclusion in a backward region like Tripura are also found very negligible. In most of the studies, it is also evident that these studies are related to larger states of our country or the country as a whole, but not properly focused on the issues associated with smaller states. 
The present study makes an attempt to understand the issues associated with Financial Inclusion in Tripura based on the perception of the stakeholders. In regard to the state of Tripura a lot of advanced and comprehensive studies have been undertaken by the researchers and institutions regarding the socio-economic problem of the state. Unfortunately, unlike the other problems the Financial Inclusion aspects of Tripura have not been able to draw the attention of the researchers to any extent. The survey of the existing literature on financial aspects indicates that at present there is no study on this issue. Therefore a comprehensive study on the issue of Financial Inclusion in Tripura is the need of the hour.

\section{OBJECTIVES OF THE STUDY}

The main objective of the study is to estimate the level of composite Financial Inclusion Index in Tripura based on established parameters. However, to be more specific the study has pursued the following objectives:

1. To understand the status of Financial Inclusion in Tripura.

2. To estimate composite Financial Inclusion Index.

3. To prepare and analyse the level of composite Financial Inclusion Index.

\section{METHODOLOGY}

In the course of analysing the issues, a number of research studies, reference books, RBI publications, Lead Bank publications, State Government and Central Government publications, notifications, reports, other published and unpublished documents relating to the study are considered. The basic databases of the analysis are taken from the SLBC Report, NEDFi databank and RBI Annual Report. The study however, considered the data of RBI Annual Reports and SLBC Report to assess the present status and to examine the level of Financial Inclusion.

There are several alternative indicators that have been used by different authors to measure the 'Index of Financial Inclusion' (IFI) in home and abroad. In the present study I have adopted a structured methodology of RBI to measure the "Financial Inclusion" in Tripura. The RBI has conducted study on "Financial Inclusion in India: A case-study of West Bengal", (Chattopadhyay, 2011), published in Reserve Bank of India working paper. The present study has taken three measurable dimensions of "Financial Inclusion" based on Banking Statistical Reports; State level Bankers Committees (SLBC) Reports and households has been selected as the basic unit for measuring "Financial Inclusion". However, the study is totally based on the selected valuable indicators, that have been showed in the below mentioned Table:

TABLE-1 INDICATORS FOR MEASURING FINANCIAL INCLUSION

\begin{tabular}{|l|l|}
\hline Indicators & Measurement \\
\hline $\begin{array}{l}\text { (i) Bank accounts per } \\
\text { adult }\end{array}$ & $\begin{array}{l}\text { Number of bank accounts per } \\
\text { adult }\end{array}$ \\
\hline $\begin{array}{l}\text { (ii) Geographic branch } \\
\text { penetration }\end{array}$ & $\begin{array}{l}\text { Number of branches per 1000 } \\
\text { km2 }\end{array}$ \\
\hline $\begin{array}{l}\text { (iii) Demographic } \\
\text { branch penetration }\end{array}$ & $\begin{array}{l}\text { Number of branches per 1,00,000 } \\
\text { people }\end{array}$ \\
\hline $\begin{array}{l}\text { (iv) Demographic Loan } \\
\text { penetration }\end{array}$ & $\begin{array}{l}\text { Number of loans per 1,00,000 } \\
\text { people }\end{array}$ \\
\hline $\begin{array}{l}\text { (v) Demographic deposit } \\
\text { penetration }\end{array}$ & $\begin{array}{l}\text { Number of deposits per 1,00,000 } \\
\text { people }\end{array}$ \\
\hline (vi) Cash-Deposit Ratio & $\begin{array}{l}\text { Cash in circulation to total bank } \\
\text { deposits }\end{array}$ \\
\hline
\end{tabular}

Source: Conrad, et. al. (2008)

Thus the details of the selected dimensions are as follows: a) Banking Penetration $\left(p_{i}\right)$

This is one of the most essential dimensions for measuring "Financial Inclusion". Perfectly, inclusive financial system ought to penetrate extensively among its users. The number of the banked population, i.e., size of adult population having a bank account is one of the indicators of measuring banking penetration of the inclusive financial system. Therefore, in an economy if the every adult person has a bank account that represents the value of this dimension would be equal to ' 1 '. In the lack of the data on banked population, we used number of bank accounts as a percentage of the total population as an indicator of banking penetration dimension. However, for the calculation of 'Index of Financial Inclusion' (IFI) I have been used both deposit accounts and credit accounts as the indicators of this dimension.

\section{b) Availability of Banking Services ( $a_{i}$ )}

In an inclusive financial system all the banking services should be available to the people freely without any hindrances of the society without any hindrances. This availability of banking services can be identified by the number of bank branches per 1000 population. The number of branches of Bank per 1000 adult population has been taken along with the number of bank branches per square $\mathrm{km}$ for measuring this dimension.

\section{c) Usage $\left(u_{i}\right)$}

The dimension of usage derives from the concept of "under banked" or "marginally banked", and it has also been observed that "in some apparently very highly banked countries, a number of people with bank account are nonetheless making very little use of the services on offer" (Kempson et. al., 2004 and Chattopadhyay, 2011). Thus only having a bank account does not make sure that the system is inclusive. It is also necessary that the banking services are effectively utilised. In order to include the usage dimension in the Financial Inclusion Index, I have considered two basic services of the banking system - outstanding amount of credits and amount of deposits.

In this study our methodology of Index of Financial Inclusion (IFI) is computed by the following formula:

$$
\begin{aligned}
& \text { IFI }_{\mathrm{i}}=1-\frac{\sqrt{(1-d 1)^{2}+(1-d 2)^{2}+\cdots+(1-d n)^{2}}}{\sqrt{n}} \\
& \text { Where, } \mathrm{d}_{\mathrm{i}}=\frac{\mathrm{A}_{\mathrm{i}}-\mathrm{m}_{\mathrm{i}}}{\mathrm{Mi}_{\mathrm{i}}-\mathrm{m}_{\mathrm{i}}}
\end{aligned}
$$

$A_{\mathrm{i}}=$ Actual value of dimension $\mathrm{I}$.

$\mathrm{m}_{\mathrm{i}}=$ minimum value of dimension $\mathrm{I}$.

$\mathrm{M}_{\mathrm{i}}=$ maximum value dimension $\mathrm{I}$.

Formula (1) ensures that $0 \leq d_{i} \leq 1$, higher the value of $d_{i}$ higher the district's achievement in dimension i. If $n$ dimension of 'Financial Inclusion' are considered, then a district I will be represented by a point $d_{i}=\left(d_{1}, d_{2}, \ldots ., d_{n}\right)$ on the n-dimensional Cartesian space. In the n-dimensional space, the point $O=(0,0, \ldots . .0)$ represents the highest achievement in all dimensions. The index of financial inclusion, IFI $_{\mathrm{i}}$, for the $\mathrm{i}$-th district, then is measured by the normalized inverse Euclidean distance of the point $d_{i}$ from the ideal point $I=(1,1, \ldots .1)$. The accurate formula is,

$$
\text { IFI }_{\mathrm{i}}=1-\frac{\sqrt{(1-d 1)^{2}+(1-d 2)^{2}+\cdots+(1-d n)^{2}}}{\sqrt{n}}
$$

In formula (2), the numerator of the second component is the Euclidian distance of $\mathrm{d}_{\mathrm{i}}$ from the ideal point I, normalizing it by and subtracting from 1 gives the inverse normalized distance. The normalized is done in order to make the value lie between 0 and $l$ and the inverse distance is considered so that higher value corresponds to higher financial inclusion.

The present 'Index of Financial Inclusion' is as follows

$$
\mathrm{IFI}_{\mathrm{i}}=1-\frac{\sqrt{\left(1-\mathrm{p}_{\mathrm{i}}\right)^{2}+\left(1-\mathrm{a}_{\mathrm{i}}\right)^{2}+\left(1-\mathrm{u}_{\mathrm{i}}\right)^{2}}}{\sqrt{n}}
$$




\section{Whereas,}

$\mathrm{pi}=$ banking penetration dimension

ai $=$ availability of banking services dimension

ui $=$ usage of banking services dimension

Depending on the values of Index of Financial Inclusion (IFI), all the districts of Tripura have been categorized into three categories, viz.:

Table-2 Scores And Levels Of Financial Inclusion

\begin{tabular}{|c|c|c|}
\hline S1. No. & Scores of IFI & Level of Financial Inclusion \\
\hline 1 & $0.5<$ IFI $\leq 1$ & High level Financial Inclusion \\
\hline 2 & $0.3 \leq$ IFI $\leq 0.5$ & Medium level Financial Inclusion \\
\hline 3 & $0 \leq$ IFI $\leq 0.3$ & Low level Financial Inclusion \\
\hline
\end{tabular}

Source:Authors observation

Thus, the Index of Financial Inclusion (IFI) has satisfied the following criteria:

(I) Should incorporate information on as lots of dimensions of inclusion as possible. Should be easy and simple to calculate.

\section{STATUS OF FINANCIAL INCLUSION IN TRIPURA}

Recently Tripura, being a state tucked away in one corner of the India's North East made a National headway in the matter of achieving "Financial Inclusion". In a first decade of 21 st century as per Report, state has shown the maximum change in availing of banking services (Ghoshal, 2013). State Level Bankers' Committee Report (SLBC) 2013 speaks of that in accordance with the RBI instructions unbanked villages having population of over 2000 were identified and allocated amongst the banks operating in the State for opening banking outlets in those villages within March 2012. In Tripura 419 such villages were identified and allocated amongst the banks broadly based on Service Area Allocation of villages. The banks have already set up banking outlets in all the 419 villages largely through Business Correspondent (BC) model and "Brick and Mortar" (B\&M) branches in some villages. According to Banking Report of Progress up to March, 2012, "BCAs were engaged in 414 villages and 449380 accounts were opened in these villages. The number has increased to 456870 at the end of September, 2012. In the meanwhile, at the directives of Indian Banks' Association (IBA), 261 villages having population of 1000 to less than 2000 were identified in Tripura for providing banking services in the second phase. The banks, however, have covered 239 villages through BC model and 13 villages through B \& M branches. The rest 9 villages were expected to cover by December, 2012".
But all these above information in no way indicate or able to capture in the actual extent and significance of such Financial Inclusion. Several different aspects or dimensions of 'Financial Inclusion' are required to be translated or incorporated preferably in a single number if any meaningful interpretation is to be drawn from a comparison. A comprehensive approach in incorporating all possible elements and aspect are thus necessary to measure and understand the actual extent and level of the significance of 'Financial Inclusion'.

However, 'Financial Inclusion' is the final outcome the fulfillment or interaction of a number of factors that contributes to and determines of actual level of people access to banking products or services. So, for understanding the significance and real tests of the single figure (that claims 100 percent Financial Inclusion in Tripura) there requires a meaningful interpretation and analysis following a comprehensive approach incorporating all possible elements and aspects that contributes to determines of actual level of 'Financial Inclusion'. Therefore, the present study entitled, "A glimpse into the level of Financial Inclusion in Tripura" has attempted to measure the extent and significance of 'Financial Inclusion' on the basis of such a comprehensive approach by developing here in the study a set of defined Indexes.

\section{COIMPUTATION OF COMPOSITE INDEX OF FINANCIAL INCLUSION}

Financial inclusion provides formal identity, access to payments system, deposits and insurance. The successful implementation of financial inclusion plans has far reaching consequences, which can help many people to come out of the abject poverty. In this study the researcher has measured the level of financial inclusion in the district level as well as block level through Index of Financial Inclusion. For the study relevant data has taken from the Census Report 2011 for measuring the block level degree of Financial Inclusion in Tripura.

The researcher has analysed the level of Financial Inclusion, through the computed value of IFI in all the districts of Tripura and to know which district leads with the high, medium, and low level of Financial Inclusion. This analysis is totally based on calculated value of District-wise Index of Financial Inclusion in Tripura. The Index of Financial Inclusion (IFI) has been computed by using the data on 3-dimensions of Financial Inclusion parameters, can be seen in the Table 3.

Table-3 District-wise Index of Financial Inclusion in Tripura

\begin{tabular}{|c|c|c|c|c|c|c|}
\hline \multirow{2}{*}{ Level of Financial Inclusion } & \multirow{2}{*}{ Districts } & $\begin{array}{c}\text { Banking } \\
\text { Penetration (pi) }\end{array}$ & $\begin{array}{c}\text { Availability of } \\
\text { Banking Services (ai) }\end{array}$ & $\begin{array}{c}\text { Usage of Banking } \\
\text { Services (ui) }\end{array}$ & \multicolumn{2}{|c|}{ IFI } \\
\hline Halues & Rank \\
\hline \multirow{2}{*}{ Medium Level (0.5 < IFI < 1) } & North Tripura & 0.62 & 0.21 & 0.93 & 0.51 & 1 \\
\hline Low Level (0.3 < IFI < 0.5) & Dhalai District & 0.00 & 1 & 1 & 0.42 & 2 \\
\cline { 2 - 7 } & West Tripura & 0.61 & 0.5 & 0.00 & 0.32 & 3 \\
\hline
\end{tabular}

Source: Basic Statistical Returns of Scheduled Commercial Banks in India, RBI \& State Level Bankers' Committee Report. UBI

*Results computed

The Table 3 shows that, there is only one district which has high level of financial inclusion ( $\mathrm{Hl} 0.5<$ IFI $\leq 1)$. The value of IFI for North Tripura is 0.51 ; which means that North Tripura district has just crossed the upper limit of medium level financial inclusion. The value of Dimension-3 is 0.933 , which implies that, this district is nearer to complete the usages of supply side parameter, but the values of other two dimensions such as 'banking penetration' and 'availability of banking services' are 0.62 and 0.21 respectively. It can be seen from Table 3 that the second hypothesis formulated as $\mathrm{H} 20.3<$ IFI $\leq$ 0.5 medium level financial inclusion. The two major districts of the state such as Dhalai District have the second rank of IFI with value of 0.42 , the other one is theWest Tripura District has 3rd rank with IFI value of 0.32 and these districts are under medium level of financial inclusion. In Dhalai District, the value of Dimension- 1 is 0 , which means that there is a low level of banking penetration and the value of Dimension-2, such as availability of banking services is 0.5 , it also implies that the dimension belongs to the upper limit of the medium level of financial inclusion. The value of the Dimension-3 is 1 ; it means the district is nearer to complete the financial inclusion in terms of usages of banking services-outstanding amount of credits and deposits. In West Tripura district, the value of Dimension- 1 is 0.62 , and Dimension- 2 is 0.5 belongs to the high level of financial inclusion. But the value of Dimension-3 is 0 , it represents there is a low levelp of financial inclusion in 
terms of usages of outstanding credits and deposits. The Table 3 also shows that, the third hypothesis formulated as H3:0 0 IFI $\leq 0.3$ the low level of financial inclusion. Only one district of the state, i.e. South Tripura has attained the fourth rank with value of 0.29 , has low financial inclusion. Among the four major districts in Tripura, South Tripura has achieved the low level of Financial Inclusion with IFI value of 0.29.

\section{ANALYSIS AND DISCUSSIONS}

The level of banking penetration in West Tripura, almost double the average level of Tripura. That is, the number of accounts per 100 adults in this district was not as good in 198081, but since 1990-91, the number of people's bank accounts significantly increased there. From the data of 2000-01 and 2010-11 it is clearly evident that, the number of accounts per 100 adult person in West Tripura district is equivalent to the maximum level of Tripura. On the other hand, the availability of banking services in this district is a little bit less than the average level of Tripura. According to the data of 1980-81 and 1990-91, most of the adult population of this district was served by fewer bank branches, because at that time there were fewer bank branches opened. Later, it was possible to reduce the number of adult population per branch, since the number of bank branches of the present district increased in 2000-01 and 2010-11. From 1980-81 to 2010-11, the data of Tripura is seen, the amount of CD ratio in the West Tripura district is much less than the maximum level of Tripura. For this reason, the usage of banking services here is zero. The rate at which people have kept their per capita deposits, they have received credits from the same amount of bank. That means, per capita credit has increased in line with the per capita deposit.

It can be clearly stated that the banking penetration services of North Tripura District is almost twice (0.62) as much than the services of Tripura average banking penetration. Moreover, the amount of usage of banking services is higher in this district as compared to the average results of Tripura. But the availability of banking services is almost twice as low as compared to the average level of Tripura. It is clear from the above discussion that the amount of banking penetration and usage of banking services is good, but the amount of availability of banking services is not very good here. The result of the usage of banking services in this district is satisfactory, because per capita deposits and credits, i.e. the ratio of Credit-Deposit is good enough. On the other hand, the number of accounts per 100 adult person is more than 0.5 , it represents the result is satisfactory. But there is less availability of banking services in this district, mainly due to the lack of number of bank branches here. For the same reason, the district level number of adult population per bank branches is more than the amount. That is, the number of bank branches is less than the population here. Moreover, more than the usage of banking services in this district compared to the average of Tripura.

It can be said that, the amount of banking penetration services in Dhalai District is 0 , where the average banking penetration of Tripura is 0.32 . The reason behind that in the year 2000-01 and 2010-11 the minimum level of total number of account per 100 adult people in Tripura has no difference between the results of the present district level. Furthermore, compared to Tripura as a whole, the number of accounts opened here is relatively less. On the other hand, the availability of banking services in this district is much better than the average availability of Tripura, almost twice as much. That is to say, theres is a large amount of adult population per bank branch. On the other hand, it is true that the maximum number of adult population in this district is served by a small number of bank branches. In relation to the usage of banking services, the value of Dhalai District is more than the average value of the entire Tripura. Because, the percentage of CD ratio here is the |www.worldwidejournals.com| same as the maximum level of Tripura. It is more obvious to say that, the per capita deposit and credit per capita in this district has increased at the same rate. But another notable fact is that, here per capita deposit and credit is less than the other districts of Tripura.

\section{CONCLUSION}

In this study an attempt has been made to measure the district wise level Index of Financial Inclusion in Tripura. It has been observed that only one district have achieved high level of Financial Inclusion and the value of IFI for North Tripura is 0.51 .It is found that the two districts of the state namely Dhalai District and West Tripura are under medium level of Financial Inclusion and only one district, South Tripura is the fourth rank with value of 0.29 , has low Financial Inclusion. Therefore the present study also inferred that apart from West Tripura District, another two districts namely as Dhalai District and North Tripura has already opened maximum nos. of bank accounts by SB accounts as well as 'No-Frill' accounts. It may be concluded that as per the SLBC Agenda Report, one of the districts in Tripura i.e. As per SLBC Report 2012, it is clear that West Tripura District has achieved $100 \%$ of Financial Inclusion by the end of 2009 and it appears that there are 170 nos. of villages having more than 2000 population have been covered by 3 Branches and 167 Business Correspondents (BCs). However, it is concluded that the achievement has been made is attributable by the role of BCs. It is inferred that all the village households ofWest Tripura District have been brought under the banking fold. This is perhaps because of the opening SB accounts, 'No-Frill' accounts, SHGs accounts and other banking accounts like SCC and KCC. In this circumstance, the maximum nos. of bank accounts has already opened in this district is lower as compare to its total nos. of families under been opened through Savings Bank (SB) accounts like-MGNREGA, pension scheme, students merit scholarship, each family has at least one account in rural areas, coverage of households under SWABHIMAN, SWAVALAMBAN and PMEGP etc. West Tripura has achieved $100 \%$ 'Financial Inclusion', but in the practical field all the village families in West Tripura are in advanced stage in respect of opening formal bank accounts.

\section{REFERENCES}

1 Agarwal, A. (2010). Financial inclusion: Challenges and opportunities. Financial Deepening (pp.1-16).23rd Skoch Summit. Retrieved June 8, 2012.

2 Bihari, D. C. (2011). Financial Inclusion-The Key To Emerging India. Asian Journal of Research In Social Sciences And Humanities, pp.47-66.

3 Chakravarty, S. R., \& Pal, R. (2010, March). Measuring Financial Inclusion: An Axiomatic Approach. Indiara Gandhi Institute of Development Research, pp.1-36.

4 Chattopadhyay, S. K. (2011, July). Financial Inclusion in India: a case-study of West Bangal.RBIWorking Paper Series, pp. 1-27.

5 CRISIL limited. (2013). CRISIL Inclusix. An index to measure India's progress on financial inclusion,pp.1-91.

6 Demirguc-Kunt, A., \& Klapper, L. (2012, April). Measuring Financial Inclusion. The Global Findex Database. Policy Research Working Paper 6025, pp.1-61.

7 European Commission. (2008). Financial Services Provision And Prevention of Financial Exclusion. Directorate-General for Employment, Social Affairs and Equal Opportunities.

8 Ghoshal, D. (2013, January 5). WHAT CENSUS DATA SHOW Consumption story intact but uneven in last 10 years. Business Standard Newspaper, p.1. New Delhi, India.

9 Government of India. (2012). CENSUS 2011 Provisional Population Totals. New Delhi: Office of the Registrar General and Census Commissioner. Ministry of Home Affairs.

10 Government of Tripura. (2008 to 2014). Economic Review of Tripura from 2006-07 to 2012-13. Planning (Statistics) Department. Directorate of Economics \& Statistics.

11 Goyal, C.K. (2013). An Investigation into Financial Inclusion Among the Rural Households in Assam. Thesis, pp.1-292.

12 Kamath, R. (2007). Financial Inclusion vis-a-vis Social Banking. Economic \& PoliticalWeekly, 42 (15),pp. 1334-1335.

13 Karmakar, K. G., Banerjee, G. D., \& Mohapatra, N. P. (2011). Towards Financial Inclusion in India. New Delhi:SAGE Publication India Pvt Ltd.pp. 14-15.

14 Mitton, L. (2008, July). Financial Inclusion in the UK: Review of policy and practice. The Homestead:Joseph Rowntree Foundation. pp. 1-6.

$15 \mathrm{Pal}, \mathrm{R}$., \& Pal, R. (2012, June). Income Related Inequality in Financial Inclusion and Role of Banks:Evidence on Financial Exclusion in India. Indira Gandhi Institute of Development Research,pp. 1-44.

16 Rao, K. G. (2007, February 3). Financial Inclusion:An Introspection. Economic and PoliticalWeekly,pp.355-360.

17 Report of the Central Board of Directors on the working of the Reserve Bank of India for the year ended August 23, 2012 submitted to the Central 

Government in terms of Section IV(24) of the Reserve Bank of India Act, 1934, p.88.

18 Reserve Bank of India. (1987, 1993, 2000). Banking Satistics - Basic Statitical Returns. Bombay: Depertment of Statitical Analysis \& Computer Services.

19 Reserve Bank of India. (2001 to 2012). Basic Satistical Returns of Scheduled Commercial Banks in India. New Delhi: Ministry of Finance.

20 Reserve Bank of India. (2006). Report of the Committee on Financial Sector Plan for North Eastern Region. Reserve Bank of India.

21 Reserve Bank of India. (2000 to 2012). Various Statistical Tables relating to Banks in India. New Delhi: Ministry of Finance.

23 Reserve Bank of India. (2008). Report of the Committee on Financial Inclusion. www.rbi.org.in

24 Reserve Bank of India. (2009). Branch Banking Statistics. New Delhi:Ministry of Finance.

25 Reserve Bank of India.. Various Annual Report from 2009-10 to 2011-12. Mumbai: Reserve Bank of India.

26 Roy, D. (2011). Financial Inclusion in India Emerging Profitable Models pp.129-134.

27 Saha, S. (2019). Measuring Financial Inclusion in Tripura.Thesis. pp.82-111.

28 Sarma, M. (2008, June). Index of Financial Inclusion. ICRIER, Working Paper, pp.1-20.

29 Thorat, U. (2007). Financial Inclusion -The Indian Experience. Financial Inclusion Conference 2007 (pp. 1165-1 172). London, UK: RBI Monthly Bulletin.

30 United Bank of India. (2007 to 2014). Various Agenda Noted for the 86th to 110th meeting of State Level Bankers' Committee. Tripura: UBI, Lead Bank Division.

\section{Websites}

1. http://databank.nedfi.com/content/banking

2. www.tripura.gov.in

3. www.nabard.org.in 